\title{
CHINA'S FOREIGN POLICY TOWARDS MYANMAR: A ROLE MODEL IN INTERNATIONAL RELATIONS
}

\author{
Mohamad Zreik \\ Central China Normal University, Wuhan, China
}

China has a large and professional diplomatic team spread all over the world. Chinese diplomacy mainly relies on soft power in its relations with international partners. Despite the unified outlines, Chinese foreign policy differs from one country to another, depending on the geographical location, the political system and the volume of trade exchange. Chinese foreign policy has gone through many stages, most notably the period of Mao Zedong who strictly applied the rules of socialism, and the period of Deng Xiaoping, known for its reform and openness policy, thus establishing a modern and more flexible Chinese system.

President Xi Jinping's term is an extension of Deng Xiaoping's rule of thumb, but with more openness to international partners and economic expansion, especially with the launch of the Belt and Road Initiative in 2013. This paper deals with China's foreign policy towards Myanmar, and refers to the development of bilateral relations and China's interest in a distinguished relationship with Myanmar. The research indicates the strategic factors that make China interested in developing the relationship with Myanmar.

Keywords: foreign policy; Southeast Asia; diplomacy; China-Myanmar relations

\section{Introduction}

Foreign policy is an integrated system for managing state affairs with countries and organizations, and it is often public. Foreign policy is not fixed, but changes according to the international and regional situation. Its formulation and application depend on a set of constitutional and legal rules.

Foreign policy is active in times of crisis and in dealings with international partners, and in many cases, foreign policies are developed in anticipation of a problem that may arise. Foreign policy is a tool for achieving national security, economic development and enhances diplomatic ties. It also aims to show the high status of a state in the international community and it may contribute to the spread of political thought or national culture.

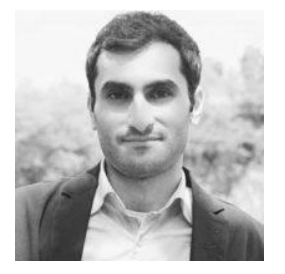

\section{Mohamad Zreik}

PhD Candidate at Central China Normal University, School of Politics and International Studies (SPIS), International Relations, Luoyu Road, Wuhan, Hubei, China.

Research interests: Chinese foreign policy; New World Order; Belt and Road Initiative; China-Arab Relations.

Additional information: the Head of the Lebanese Community in Wuhan; Member of the International Federation of Arab Journalists and Writers, Friends of China (July 2018 August 2020).

E-mail: mohamadzreik1@gmail.com 


\section{CHINA'S FOREIGN POLICY TOWARDS}

Countries tend to achieve the goals of their foreign policy through diplomacy, enhanced bilateral relations, conference diplomacy, and diplomacy of international organizations and so on. Foreign policy goals can also be achieved by economic means, such as granting aid or the opposite - imposing sanctions. Media and psychological warfare also have an important role in contributing to the achievement of foreign policy goals. Another means is to use the intelligence to collect strategic information. Sometimes violence may serve as a tool to demonstrate discord and support opposition groups inside a country (Morgenthau, 1967).

Myanmar and China have borders and kinship relations, so Chinese-Myanmar relationship is quite well-established, with the common history full of friendship and events that in the interest of the two peoples. Many studies and reports indicate the depth of the strategic relationship between these two countries, which has become more solid due to the relatively recent Belt and Road Initiative.

China is the most important country for Myanmar due to its enormous economic exchanges and joint ventures, and also China's positive role in resolving the internal conflict (Kudo, 2006). Some historical documents refer to the relations that existed between ancient China and the Kingdom of Pagan (or Bagan) which was established in 849, so this relationship is truly ancient and it is impossible to be negatively affected by the regional and/or international policies of various other countries. The state policy always aims to achieve national interests.

For Myanmar, it is in its vital interest to establish distinguished and long-lasting relations with the Chinese (Geng, 2007). The Myanmar government was among the first to establish diplomatic relations with the People's Republic of China, and it was agreed that the relations would be based on the Five Principles of Peaceful Coexistence: through mutual respect for national sovereignty, settlement of disputes by diplomatic means, noninterference in internal affairs, mutual benefit and peaceful coexistence (Sino-Burmese Joint Declaration of the 29th of June 1954).

China is Myanmar's first trading partner (Brocková et al., 2020). Although Myanmar is not an important trading partner for China, the importance of this country in Chinese foreign policy is increasing due to its geography, national security, good neighborhood relations, and China's economic expansion through the Belt and Road Initiative. China-Myanmar relations have developed greatly, especially thanks to the increasing economic exchanges. The State Law and Order Restoration Council or the State Peace and Development Council had the most important role in strengthening this relationship. By the end of the 1980s, ChineseMyanmar relations entered an advanced stage of strategic cooperation (Hilton, 2013, 1).

Myanmar has suffered from the US sanctions then. China has always been by Myanmar in such times of crisis. Some experts directly suggest that Chinese and Myanmar regimes are similar in such features as dictatorship and tight control. Therefore, the West does not accept cooperation with a dictatorial regime as this does not identify with Western policies. However, the geographical location of Myanmar and the increasing economic relations between China and Myanmar made the West reconsider its attitude. When the accusations were leveled against the Myanmar regime in part of violating human rights, they led to great international pressure on Myanmar and the suspension of international aid. However, others consider Western sanctions as an open opportunity for the Chinese to enter Myanmar and fill this Western void (Geng, 2007). 
China has many huge investment projects in Myanmar, in addition to infrastructure projects, for example, the Myitsone Dam. These projects are part of Chinese-Myanmar strategic government cooperation (Hilton, 2013, 1). China is interested in Myanmar, as it has a strategic geographic location in addition to natural resources and long-standing links between the two governments (Geng, 2007). China has developed its maritime policy, so it needs to cooperate with Myanmar for easy access to the Indian Ocean and the Pacific Ocean. Myanmar has thus turned into a part of Chinese maritime strategy. Chinese foreign policy targets Myanmar in order to expand its influence by land and sea and to reach the Myanmar Coco Islands. Consequently, Myanmar is at the core of a Chinese strategic plan aimed at linking China, Myanmar, Thailand and Laos (Singh, 2013). Some reports indicate Chinese ambitions go far beyond economic cooperation to include military expansion in the Indian Ocean region, and this may explain the conflict of Chinese and Indian interests at multiple occasions (Shee, 2002, 33-53; Jančíková et al., 2016 ).

This paper describes Sino-Myanmar relations and analyzes the position of Myanmar within the framework of Chinese foreign policy. This paper relies on both primary and secondary Western and Asian sources. We did our best to make sure all opinions are presented without a prejudice to a specific political party or vision.

\section{Theoretical basis of the study}

Chinese foreign policy dates back to the historic times of the famous Silk Road. China has long been known for its openness to people and peaceful communication. However, modern Chinese foreign policy has arisen since 1949, that is, since the establishment of the People's Republic of China. When the People's Republic of China was established, China started following a rather "black and white" policy. Every country following a different political system was considered an enemy and subordinate to imperialism, directly or indirectly, but this policy changed later on due to the increasing Chinese economic interests in other countries (Hongwei, 2009, 1-12).

China now adopts a foreign policy based on ancient cultural heritage and moral values that defines the frameworks of the Communist Party of China. Chairman Mao Zedong has called for a cultural revolution and to keep pace with modern development without moving away from the roots, which is up to the Five Principles of Peaceful Coexistence among Countries that are the main pillar of China's interaction with various countries. These foundations were also laid by Chinese political theorist Zhou Enlai in the 1960s. In its foreign policy, China focuses on increasing cooperation with the third world countries for the establishment of strategic alliances and easy access to natural resources (Zheng, 2005, 1824).

In 1984, China developed more industrial cities and opened more to the world, primarily through 14 Chinese coastal cities. With the beginning of the 1990s, the priority was to develop the technology sector to keep pace with the world progress (Macfarquhar, 1997, 488-489).

In 1954, China, Myanmar and India agreed on the five principles of peaceful coexistence. These principles are based on respect for national sovereignty and territorial integrity, mutual non-aggression, non-interference in internal affairs, equality and mutual benefit, and peaceful coexistence (Geng, 2006). These principles led to the formation of a new theory in international relations. China has embraced soft power as an effective tool in 


\section{CHINA'S FOREIGN POLICY TOWARDS}

diplomacy and international relations. These five principles were reflected in the goals and principles of the United Nations Charter, and they are considered to be the principles of international law that enjoy openness and inclusion, they also represent the concepts of sovereignty, justice, democracy and the rule of law. These principles help China's outreach to countries in general and to neighboring countries in particular.

The main source of Chinese political philosophy is drawn from the teachings of the Chinese philosopher Confucius. His political authority has worked to adopt human and moral teachings and integrate them with political engagement in other countries, in addition to applying them to Chinese domestic politics. The most important goal of political power is to reduce the level of poverty through fair policies. Zhang Zhongjing and Xuanzang (10171073) were among the most prominent thinkers who drew the identity of China's foreign policy during the Han dynasty, Han Yu from the Tang Dynasty (1635-1704), and some philosophers from the Qing Dynasty. These were the actual founders of Chinese foreign policy.

Chinese politics is considered to be a unique mixture between diplomacy and philosophy. It is a result of ancient Chinese teachings, which is considered to be the oldest Asian philosophy. The internal and external Chinese policies do not deal with people and countries on the basis of religion. Anthropologists have multiple times emphasized that there is no word for religion in Chinese. This indicates that China, since its very beginnings, has united all the Chinese people under one Chinese culture (Hsu, 1991). In this context, Chinese President Xi Jinping stated that "China boasts a long traditional culture, and China will create a new glory of its culture. Confucian thought can play a positive role in China's development today".

Chinese leader Deng Xiaoping formulated a Chinese policy that was based on openness, communication, and coexistence between the one-party system and the market economy system (André, 2009, 54-55). The introduction of some elements of the capitalist system to China included the concept of incentive into workers' culture and the idea of cooperation with the powers that represent the private sector, cultural openness to all countries of the world, openness of Chinese economy to all other markets, retaining traditional Chinese teachings and not abandoning them. All of these factors led to the formulation of a new system which is considered to be a "socialist system with Chinese characteristics" (Saich, 2004, 57). Deng Xiaoping focused on economic reform and the introduction of new economic patterns that do not prioritize politics, so China has made great economic progress.

\section{Factors Affecting China's Foreign Policy}

China's foreign policy is the result of various geographical, economic and commercial factors. China does not follow the same method of dealing with all countries, but in general, its policy is based on dialogue and the preference of economic interests. For example, China's foreign policy towards the United States is different from that towards Russia, and this is due to geopolitics, economic interests, and the nature of political systems in these countries. Under Chinese Presidents Jiang Zemin and Hu Jintao, China pursued the policy of opening up to the international community (André, 2009, 29). For example, in 2001, China joined the World Trade Organization. 
China's "neutral" foreign policy was one of the key reasons for its economic rise and peaceful engagement with the West. Despite the political interests that require China to take the risk, Chinese decisions are characterized by wisdom (Ekman, 2012, 58).

In the Syrian crisis, for example, Russia intervened directly and militarily while Chinese intervention remained fully political as Chinese diplomacy has sought to end the crisis (Zreik, 2019, 56-65). China has pursued the policy of peaceful communication and civilized openness since the Silk Road to this day. Despite its technological, economic and military superiority, it has not started wars in other countries. This indicates a new pattern in international relations that China is now establishing. Soft power has become a relatively new pillar in contemporary international relations. Despite the great superiority, China has always followed diplomacy in dealing with the United States. This has found its manifestations in the recent trade war between these two countries.

China is increasing student exchange programs with the third world countries that are at the core of Chinese soft power. For example, in China, there are many Myanmar students who benefit from Chinese government scholarships (Mingjiang, 2009).

Western policy has been traditionally demonstrating some support to opposition in Xinjiang and Hong Kong, and this has pushed China to adhere to its nationalism, national sovereignty and territorial integrity even stronger. Chinese President Xi Jinping's policy is also on this path. The current Chinese policy is largely based on soft power, and China has demonstrated the success of this strategy in economic expansion, domestic unity and achieving other strategic goals (Youling, 2011, 24).

In 1993, Wang Huning put forward the idea of soft power in an article published by (Hongyi \& Yiyi, 2012, 11). Since the reform and the opening-up policy introduced in 1979, Deng Xiaoping's goal has been to maintain stability, which is a major prerequisite for Chinese economic and social development. With the arrival of Chinese President Xi Jinping to power, he developed China's foreign policy by announcing the Belt and Road Initiative in 2013. This huge and ambitious project has greatly increased China's economic role and its geopolitical importance (Cai et al., 2015, 25-29).

Foreign policy is shaped by multiple geographic and demographic determinants. China is the third largest country (after Russia and Canada). It occupies a distinguished geographical location on the Asian continent, where it borders 14 countries, the majority of which are regional powers such as India and Russia.

China's foreign policy has also much to do with military capabilities. China has a strong army and a powerful military arsenal. In 1964, China joined the so-called "nuclear club", and this fact has seriously contributed to strengthening its international position. Thus, the option of hard power remains on the table for China, but it remains in place for the worst case scenario only.

\section{China's Current Foreign Policy}

Chinese administration nowadays pursues a foreign policy based on cooperation and solidarity with countries and peoples, especially developing ones. China has distinguished relations with neighboring countries and engages in resolving the disputes that may arise in its region diplomatically, without violence. Through this policy, China contributes to a new world order based on respect, economic cooperation and win-win situations. For some countries, China has even become a model of a peaceful country thanks to its wise approach 


\section{CHINA'S FOREIGN POLICY TOWARDS}

to international relations. PRC has always been a mediator making efforts to resolve disputes between countries in a diplomatic way.

The former Chinese President Jiang Zemin has stipulated the main principles of China's foreign policy through rational assessment of the international situation. Chinese interests should be supreme for maintaining national security and territorial integrity of China. The document by President Jiang Zemin also stipulated not to react in a hasty manner but rather stay calm and rational. Other interesting statements by Jiang Zemin are: not all elements of Chinese power are public, and the use of time can be in favor of China. Jiang Zemin was a distinguished president thanks to the peaceful and diplomatic foreign policy he was pursuing towards various international parties.

Since the mid-1990s, China has pursued a new foreign policy. It has started to increase the size of its bilateral relations. The country has signed many trade and security agreements and joined international organizations, such as the World Trade Organization, establishing the Shanghai Cooperation Organization, cooperation with the ASEAN and the Pacific Cooperation Organization, and organizing the China Africa Forum. Thus, China has become an important player at the international stage through its foreign policy which seeks to engage with the international community (Yuyan, 2019).

Chinese officials have, inter alia, stated that "China will not allow the United States to make us an enemy of it." China has always been trying to avoid the policy of hostility and wars, and instead, followed the soft diplomatic power to resolve differences. In the previous several years the United States pursued quite a harsh policy with China on many issues such as the South China Sea, Hong Kong, Tibet, Xinjiang as well as the issues of freedoms and human rights (Green et al., 2015).

\section{The Importance of Myanmar on Chinese Geopolitical Map}

Myanmar is an important country for China because of geographical location and natural resources. China intends to raise the level of its relations with Myanmar to become a strategic ally. The launch of the Belt and Road Initiative has also increased the importance of Myanmar to China. China has been the big brother of Myanmar, especially during the economic blockade imposed by the United States of America.

Myanmar recognized the People's Republic of China in December 1949; this bilateral relation is constantly evolving. In 1954, the first trade treaty was signed between these two countries. In 1961, the border agreement between the two countries was ratified (Shambaugh, 2000, 218). China is the most important country for Myanmar, as it is the first trade partner and has an important political role. Also, China has the longest border with Myanmar, 2227 $\mathrm{km}$ in total. Hence, the relations are of strategic importance for both countries and are impossible to roll back, especially with China's great economic progress (Earth's Right International, 2008).

In 1988, the border trade was officially opened. In September 1993, Myanmar opened a consulate in Kunming, and in 1994 a Chinese consulate was opened in Mandalay. In 1998, Myanmar and China signed a \$250 mln loan agreement, according to which Beijing also provided 280 megawatt from hydroelectric power plant near Pyinmana. In December 2001, Chinese president visited Myanmar and an economic and border agreement was signed. In December 2009, China and Myanmar signed the agreements on cooperation in trade, transportation infrastructure, financial sector, hydropower generation, energy, oil and gas 
(Aibing, 2011). The Myanmar people describe this bilateral relationship with the phrase "Pauk-Phaw", meaning "brothers", considering that China is a brother to Myanmar and not a foreign country. On this basis and with this attitude in mind, Myanmar people build their foreign policy towards China (Aung, 2011).

In February 2010 two sides also signed the Memorandum of Understanding on the implementation of Upper Thanlwin also known as the Kunlong Hydropower Project. In April of the same year, an agreement was signed between Chinese, Myanmar and Thai companies on the implementation of the Hatgyi Hydropower Project. In May, China and Myanmar signed a memorandum of understanding on the Mawlaik Hydropower Project and the Kalewa Coal-fired Power Plant Project. In June, a profit-sharing contract on the production of oil and gas from Block F of onshore territory was signed between Chinese and Myanmar companies.

In April 2011 it was agreed that Chinese companies will start working on the MuseKyaukphyu railroad project. In May of the same year, it was agreed to enhance military cooperation between the two countries, and a memorandum of understanding was signed between the two countries in the presence of Myanmar President during his official visit to China. There is currently great military cooperation between China and Myanmar, in addition to China's support for Myanmar intelligence.

This cooperation indicates China's confidence in the alliance with Myanmar. The alliance with Myanmar contributes to China's easy access to many strategic locations, such as the Malaga strait, for example. It is worth noting that China has not stopped supporting Myanmar government and people economically and politically. China is a fundamental supporter of the political system in Myanmar because it safeguards China's interests and contributes to political harmony between the two sides.

China has been on the same side with Myanmar in international affairs and has been defending Myanmar government in international discussions. China made efforts to participate in resolution of the internal conflict in Myanmar (Lynch, 2007). Myanmar is a neighboring country; so if the situation in Myanmar deteriorates, it will negatively affect China too.

In April 2016, Chinese Foreign Minister Wang Yi visited Myanmar, the first official visit of a Chinese foreign minister since the government of the National League for Democracy assumed office. In August of the same year, President U Htin Kyaw formed a 20member commission to assess proposed hydropower projects on the Irrawaddy River. In November, during a formal meeting between the two countries, China was determined to end the conflict in Myanmar and settle the border problem. China's plan to bring peace to the region will not succeed without the participation of Myanmar in this strategy because of its geographical location and its important political and cultural role regionwide (Hongwei, 2009, 1-12).

On April 25, China proposed to contribute to resolving the dispute between Myanmar and Bangladesh over the issues with the Rohingya (Jennings, 2019). On the second day, after a meeting between Chinese legislator Zhang Dejiang and the Chairman of the Legal Affairs and Special Cases Assessment Commission U Shwe Mann in Beijing, the two sides agreed to strengthen bilateral relations. On August 30, Britain called for an emergency session of the UN Security Council regarding the situation in Myanmar, but China opposed it and asked the United Nations not to interfere in Myanmar's internal affairs. On 8 September, Chinese embassy opened its first interim liaison office in Naypyidaw. 


\section{CHINA'S FOREIGN POLICY TOWARDS}

In April 2017, the Kyaukphyu-Kunming oil pipeline agreement was signed, and Myanmar's State Counselor DawAung San SuuKyi met Chang Zhenming, the chairman of the China International Trust and Investment Company for a deep-water Seaport project in Kyaukphyu SEZ and transportation and infrastructure development in Myanmar. Nowadays China has huge investment and infrastructure projects in Myanmar such as the Letpadaung copper mines in Monywa and Myitsone Dam (Hilton, 2013).

China's foreign policy towards Myanmar has been always peaceful, and the primary goal is stability and win-win. China cannot pursue a hostile policy, as this would endanger its own interests in the region and have a negative impact on Chinese security and economy. Within the framework of the Belt and Road Initiative, China has developed transport lines linking it to Myanmar down to West Bengal Bay, so China has expanded geographically in a peaceful and diplomatic way.

\section{China's Foreign Policy towards Myanmar}

Chinese official reports indicate that China pursues the policy of friendship and brotherhood towards Myanmar, and Chinese officials stress that this policy will not change in the future. China intends, through its policy, to strengthen the historical ties between the two countries and deepen their mutually beneficial cooperation. China supports Myanmar's efforts to achieve stable development and improve people's living conditions. Some Myanmar references indicate that the official Sino-Myanmar relations date back to the year 802 A.D., after the Pyu delegation visited the Tang rulers. This event formed the first pillar of the bilateral relationship and indicated the long-standing Myanmar openness to the Chinese and the desire of Myanmar rulers to establish good relations with China ages ago. In 1769, the Treaty of Friendship and Peace was signed between China and Myanmar, providing for the establishment of friendly relationship, respect for national sovereignty and non-aggression. The relations remained stable until 1874 with the British colonial rule (Singh, 2003).

Trade exchange has always accompanied the political openness between the two countries and it was concentrated in the city of Yunnan. However, the official trade openness dates back to the eighteenth century, as economic relations developed and remained in place throughout the British colonial period to this day. Myanmar gained independence in 1948, and in 1949 already it was one of the first countries to recognize the People's Republic of China. This official political stance in support of the People's Republic of China has had a positive impact on the development of the bilateral relations. Despite the unequal economic exchange, Myanmar has a privileged position on Chinese geopolitical map. Myanmar is the backyard of China, so security in Myanmar is equivalent to Chinese own national security. Chinese leaders have attached great importance to the relationship with Myanmar. In June 1954, Zhou Enlai established a more open policy in relation to Myanmar government during an official visit, and in November $1954 \mathrm{U}$ Nu visited China with an official visit. These visits created the atmosphere of stability which contributed to rapid development of the bilateral relations (Maung, 2007).

Until 2011, Myanmar used to be under a dictatorial rule and was called Burma after the Burmese ethnic group, which forms the majority of Myanmar population to date. Consequently, freedoms were almost non-existent, and there was no room for broad political participation, in addition to violation of human rights. The country has also suffered from the 
US economic sanctions. Many studies indicate that this situation was appropriate for the Chinese to raise bilateral cooperation, develop relations and fill the Western void. China has become the number one trading partner and a strategic political ally of Myanmar government (Geng, 2007). In 1954, the Five Principles of Peaceful Coexistence between the People's Republic of China and Myanmar were signed. These principles frame the bilateral relationship and put it on the right track as it is today.

The permanent military coordination between China and Myanmar indicates the depth of the bilateral relationship, as Myanmar is the key partner of China (Geng, 2006). China's relentless endeavors to resolve the internal conflict in Myanmar signal that China is interested in stability in this country, especially with the launch of the Belt and Road Initiative and the establishment of the China-Myanmar Economic Corridor. China is one of the most important countries for Myanmar, due to the advanced economic and trade relations, however, Myanmar also has good relations with India and Thailand. The geography factor has pushed China to place Myanmar at the center of its foreign policy. Historically, the Southeast Asian countries have favored bilateral relations with countries over multilateralism in international relations. The presence of two great powers (China and India) on the borders of Myanmar has led to competition for influence in this country (Geng, 2006).

China's decision to establish a seaport in Kyukpiyu on the Rakhine Coast in the Bay of Bengal shows that China has become a major partner for Myanmar. China would develop infrastructure in Myanmar and establish many other projects related to energy and trade. This port is part of the Belt and Road Initiative. China has become a strong country in South Asia after establishing seaports in Sri Lanka, Pakistan and Myanmar, and there is also a seaport project to be implemented in Bangladesh (Beech, 2018). The Indo-Chinese rivalry manifests itself indirectly in Myanmar, through investments and projects undertaken by both countries, especially mega projects in Rakhine State. Some consider that Sino-Indian policies in Myanmar can sometimes complement each other, so it should not necessarily be considered as competition (Lees, 2006). China pursues a unique foreign policy towards Myanmar through the political support of Myanmar government in international forums and permanent military cooperation between Chinese and Myanmar armies as well as through China's building an important transportation network and establishing mega projects that would eventually turn Myanmar into a great country in Southeast Asia (Perlez \& Feng, 2013).

\section{Conclusion}

Chinese administration pursues a peaceful foreign policy and cooperates with all international partners available. China has the largest international diplomatic representation, due to its participatory policy, its respect for the sovereignty of states, and the policy of noninterference in internal affairs of other countries. The bilateral relationship between China and Myanmar is long-standing.

This paper refers to the most prominent events in the common history of the two countries in question. China meaningfully contributes to Myanmar's economic rise. Relations between these two countries have been developing even more actively after the launch of the Belt and Road Initiative due to the strategic geographical location of Myanmar (Garver, 2018). Myanmar is a necessity for China, especially with regard to transportation because it has a vital location on the Chinese map. Myanmar has always been an attraction for 


\section{CHINA'S FOREIGN POLICY TOWARDS}

international powers, as this country links South Asia and Southeast Asia. By now, China and Myanmar have a long list of treaties and agreements already signed and approved, such as the Treaty of Peace and Friendship and the Five Principles of Peaceful Coexistence. In addition to the joint huge economic projects, China is the number one trading partner for Myanmar.

Apart from its obvious economic interests, China has an important political role in Myanmar. For example, China plays a positive role in resolving the internal conflict in Myanmar. For the Chinese, security in Myanmar is equivalent to Chinese national security. Myanmar is rich in natural resources and has a strategic geographic location which further encourages the Chinese to invest. The Myanmar people describe the bilateral relationship as "Pauk-Phaw", meaning "relationship of brotherhood". China has always been a faithful friend of Myanmar and has remained by its side in times of economic crises and international pressure, so Myanmar has a special relationship with China too. Long-term and stable friendship with Myanmar allows China access to the Bay of Bengal and other strategic areas in the region, and this fact benefits the joint projects of the two Asian countries in question.

\section{References:}

Aibing, G. (2011). China Power Investment Says Myanmar Dam Halt Is Bewildering. Bloomberg L.P.

André, P. (2009). la notion d'Etat dans la pensée politique chinoise et ses conséquences sur la scène internationale, science politique. Université Paris-Est, 54-55.

Aung, M. (2011). In the Name of Pauk-Phaw: Myanmar's China policy since 1948. Singapore: Institute of Southeast Asian Studies.

Beech, H. (2018). We Cannot Afford This: Malaysia Pushes Back Against China's Vision. The New York Times, August 20.

Brocková, K., Grešš, M., Karpenko, L. \& Lipková, L. (2020). Qualitative Changes in China’s Foreign Trade in the Era of "New Normal". Journal for economic theory, economic policy, social and economic forecasting, 68(10), 1126-1151

Cai, C.L., Li, H.Y. \& Xu, S.H. (2015). A review on "the Belt and Road Initiative" studies in China. Journal of Kunming Univ. Sci. Technol, 6, 25-29.

Earth's Right International (2008). China in Burma: The Increasing Investment of Chinese Multinational Corporations in Burma's Hydropower, Oil and Natural Gas, and Mining Sectors. 3-44.

Ekman, A. (2012). China's Two-Track Foreign Policy-From Ambiguous To Clear-Cut Positions. Asie, Visions, 58.

Garver, J. (2018). China's Quest: The History of the Foreign Relations of the People's Republic.

Geng, L. (2007). Sino-Myanmar Relations: Analysis and Prospects. Culture Mandala, 7(2)

Green, M. Glaser, B. \& Poling, G. (2015). The U.S. Asserts Freedom of Navigation in the South China Sea, Asia Maritime Transparency Initiative (October 27, 2015).

Hilton, I. (2013). China in Myanmar: Implications for the Future, Norwegian Peace Building Research Centre. Centre for East-West Cultural and Economic Studies, 7(2), 1-15. 
Hongwei, F. (2009). China-Burma Ties in 1954: The Beginning of the Puak Phaw Era ICS Working Paper 2009-21, 1-12.

Hongyi, L. \& Yiyi, L. (2012). China's soft power and international relations. Routledge.

Jančíková, E., Raneta, L. \& Braga, D. (2016). Internationalization of renminbi and the real effective exchange rate. Journal for economic theory, economic policy, social and economic forecasting, 64(7), 666-685.

Jennings, R. (2019). Myanmar, Though Suspicious of China, Edges Closer to Beijing for Safety. Voice of America, December 25.

Kudo, T. (2006). Myanmar's Economic Relation with China: Can China Support the Myanmar Economy? Discussion Paper, 66.

Lees, G. (2006). India and China compete for Burma's resources, World Politics Review, 21.

Lynch, C. (2007). Russia, China veto resolution criticizing Burma. Washington Post, January, 13.

Macfarquhar, R. (1997). The politics of China. The Eras of Mao and Deng Cambridge University Press, 488-489.

Maung, M. (2007). Asian Regional Powers: Junta's Lifelines but Not Change Agents? Myanmar and Its Foreign Policy.

Mingjiang, L. (2009). Soft Power Lexington Books.

Morgenthau, H. J. (1967). Politics among nations; the struggle for power and peace. New York: Knopf.

Perlez, J. \& Feng, B. (2013). Under Pressure, China Measures Its Impact in Myanmar. The New York Times, May, 18.

Saich, T. (2004). Governance and politics in China. New York, Palgrave Macmillan, 57.

Shambaugh, D. (2000). Power Shift: China and Asia's New Dynamics. Nazrul Institute, 218.

Shee, P. K. (2002). The Political Economy of China-Myanmar Relations: Strategic and Economic Dimensions. Annual Review of International Studies, 1 (10), 33- 53.

Singh, D. (2003). Southeast Asian Affairs 2003. Available online at: https://bookshop.iseas.edu.sg/publication/1477.

Youling, L. (2011). External Communication as a Vehicle For Disseminating Soft Power. State University of New York at Buffalo, Dissertations Publishing.

Yuyan, Z. (2019). China remains committed to greater openness, China Daily, June, 20.

Zheng, B. (2005). China's Peaceful Rise to Great-Power Status. Foreign Affairs, 84 (5), 18-24.

Zreik, M. (2019). China's Involvement In The Syrian Crisis And The Implications Of Its Neutral Stance In The War. Journal of Political Science, 21 (1), 56-65.

Paper submitted

Paper accepted for publishing

Paper published online
12 December 2020

18 February 2021

31 March 2021 